\title{
An Analysis of Pre-Service Mathematics Teachers' Desmos Activities for Linear Programming Lesson
}

\author{
Desyarti Safarini TLS ${ }^{1 *}$ (D), Tatang Herman ${ }^{2}$ (1)
}

${ }^{1}$ Sampoerna University, INDONESIA

${ }^{2}$ Universitas Pendidikan Indonesia, INDONESIA

*Corresponding Author: desyarti.safarini@sampoernauniversity.ac.id

Citation: TLS, D. S., \& Herman, T. (2020). An Analysis of Pre-Service Mathematics Teachers' Desmos Activities for Linear Programming Lesson. International Journal of Pedagogical Development and Lifelong Learning, 1(1), ep2002. https://doi.org/10.30935/ijpdll/8312

\begin{abstract}
This qualitative study was aiming to analyze digital learning activities developed by pre-service mathematics teachers for linear programming lesson. The research participants were five pre-service teachers who assigned individually to develop learning activities for Linear Programming lesson by using Desmos Activity Builder. The analysis was conducted by adopting the Triple E framework, which measure how well the Desmos Activities are helping students engage in, enhance, and extend the lesson. It was found that all pre-service teachers have reached the green level of the Triple E Framework. Future improvement is needed, especially in the extension aspect. This study shows that there is potential to optimize pre-service mathematics teacher readiness to develop technology by providing opportunities for them to think about, design, experience, and reflect on how they can use technology for learning and teaching.
\end{abstract}

Keywords: desmos, activities, linear, programming

Received: 22 Apr. 2020 - Accepted: 27 May 2020

\section{INTRODUCTION}

Many studies have found that students have difficulty drawing graph and finding feasible regions of linear programming problems. The United States National Assessment of Educational Progress (NAEP) (Carpenter, Corbitt, Kepner, Lindquist, \& Reys, 1981) found that only $18 \%$ of the 17 -year-old students were able to draw a graph of linear equations. NCTM (2000) emphasizes that it is essential for teachers and students to use technology in mathematics teachinglearning regularly. Technology can support mathematical activities, which are reasoning, arguing, solving problems, and communicating mathematically. Effective teachers can optimize the potential use of technology to develop students' understanding, promote students' interest, and improve student proficiency in mathematics. When teachers use technology strategically, they have provided more significant opportunities for students to learn mathematics.

Merely having access to technology does not adequately guarantee the use of optimal technology in the learning of mathematics. Teachers are instrumental in the successful use of technology in mathematical learning (King-Sears, 2009; Roschelle et al., 2010; Suh, 2010). Teachers should be able to determine when and how technology can increase the chances of students with mathematics (ISTE, 2008). In the context of Indonesia, the 2013 curriculum demands subject teachers to integrate information and communication technology (ICT) content in the lesson. Therefore, teachers and pre-service mathematics teachers need to obtain adequate professionalism program to ensure they can use the technology effectively.

As stated by the Technology Committee for the Association of Mathematics Teacher Educators (2005), teacher education institutions can strengthen pre-service teachers' knowledge and skills of effective use of technology in mathematical learning. This can be done by enabling pre-service teachers to explore and learn mathematics using technology in a way that builds self-confidence and understanding of technology and mathematics, model the use of various recent technological applications as tools to develop a deep understanding of mathematics in various contexts, help pre-service teachers make informed decisions about the appropriate use of technology and is effective in mathematical learning; and provide opportunities for preservice teachers to develop and practice learning that utilizes technological capabilities to enrich and improve mathematical learning. Thus, teacher education institutions or Lembaga Pendidikan Tenaga Kependidikan (LPTK) can organize lectures that promote prospective teachers to develop technology for interactive mathematical learning.

One of the private LPTK in Jakarta strives to perform lectures that open access for pre-service teachers to develop technology for effective and interactive mathematics learning. In Linear Programming courses, the pre-service mathematics teachers were not only learning about the content but also learn to develop technology for teaching-learning of linear Program for high-school students in grade 10. The associated technology that used for this purpose was the Desmos Activity Builder. 


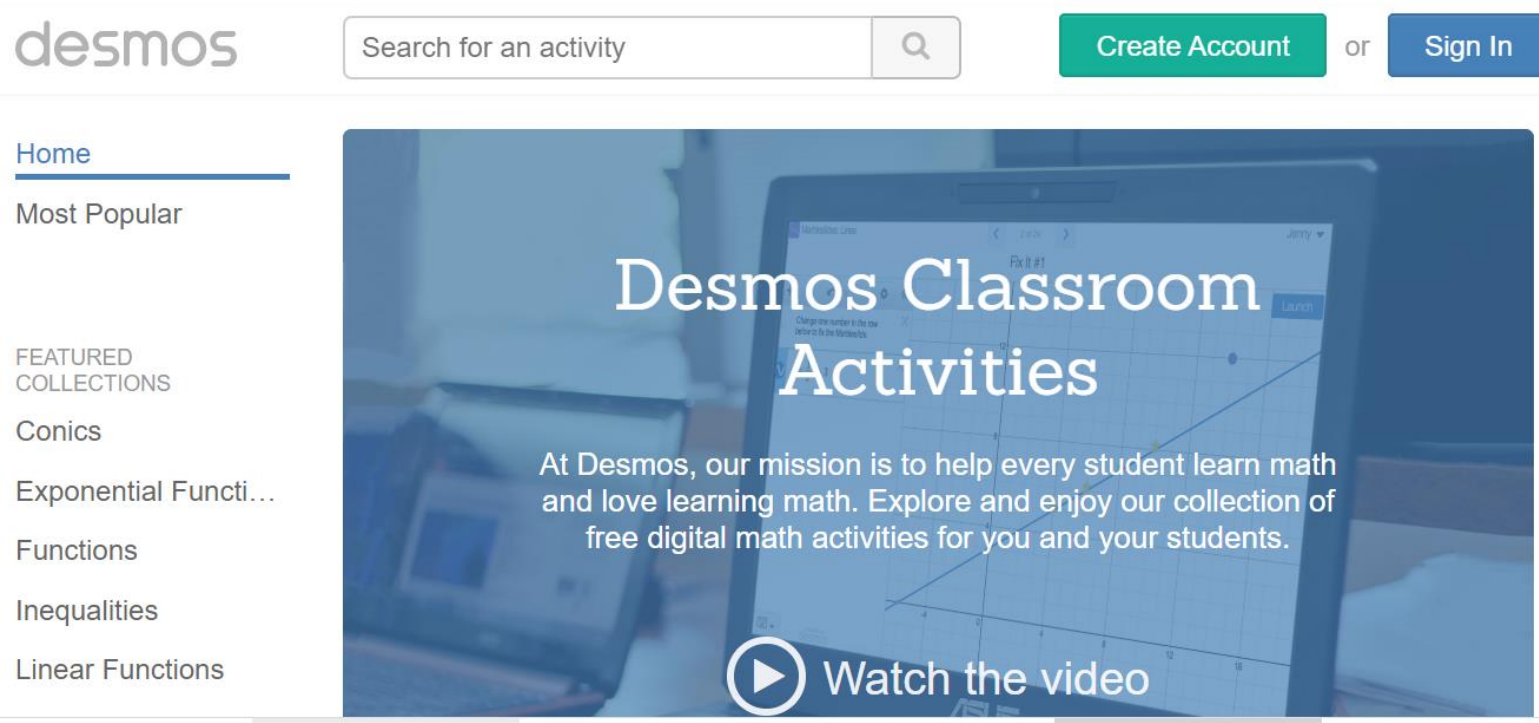

Figure 1. Desmos Activity Builder homepage at https://teacher.desmos.com/

Lecturers have been familiarizing the pre-service teachers using all features of the Desmos Activity Builder.

Desmos Activity Builder is a website-based technology that is very useful to make students participate actively in mathematics learning. Desmos has many advantages over other programs or applications, which are free, easy to use, intuitive, and powerful tools for creating graphics (Ebert, 2014). Desmos Activity Builder is also proven to provide opportunities for students to learn mathematical concepts productively and profoundly. Also, teachers can know the progress of learning every student in real-time (Jon ORR, 2017). According to Gulati (2017), the excellence of Desmos Activity Builder is that students can experience multiple learning opportunities. Students can use the graphs feature to create plots, convey their ideas, share their findings with other students and review their learning progress. Teachers can also see the progress of learning every student during the class. Teachers can use the pause feature to ensure that each student is focused on class discussions and respond to each other's findings. Teachers can also identify students who need individual support. Students also have the opportunity to learn according to their abilities and pace. Teachers are expected to tailor special activities to their students and also meet each student's learning needs.

Based on the above explanation, Desmos Activity Builder is a free (open source) website-based application which capable of facilitating interactive mathematical learning activities, informing students' learning progress in real-time mode, and free access for students with mathematics. Taking into consideration the excellence of Desmos Activity Builder on mathematical teaching-learning, this research is aiming to conduct studies on the analysis of pre-service teachers' Desmos activities for linear programming lesson. The results of this study are valuable for further study of the technological pedagogical content knowledge (TPACK) competency of mathematics pre-service teachers. Additionally, this study provides a recommendation to the associated LPTK on how to improve the competence of prospective teachers in using and developing technology for mathematics lesson. The research question for the study was: how well the Desmos Activity Builder developed by mathematics pre-service teachers meet the learning goals in Linear Programming lesson according to the Triple E Framework?

\section{DESMOS ACTIVITY BUILDER}

Desmos is known as a website that provides free online graphing calculator. Desmos has the vision to support each student in studying mathematics and liking it. To achieve that vision, Desmos developed a new program called Desmos Activity Builder, which facilitating teachers to easily develop interactive and meaningful digital mathematical learning activities. Desmos learning activities can encourage students to actively create mathematical ideas rather than getting knowledge from the teacher. Students are also stimulated to share ideas, create, and ultimately build understanding and generate new knowledge.

Not only students gain benefits from Desmos Activity Builder, but the teacher also gained experiences in creating a series of mathematical digital learning activities that emphasize the exploratory, analytical and collaborative aspects. Furthermore, the teacher can monitor and evaluate each student's learning progress in real-time mode through the dashboard feature of Desmos Activity Builder. Teachers can easily find out if there are students who have difficulties or have misconceptions so that the teacher can immediately provide the support needed by the student. To avoid misconceptions and to scaffold students through the given activities. Teachers can create digital learning activities in Desmos Activity Builder by accessing the https://teacher.desmos.com/page and then create for a free account. Figure 1 shows the homepage of Desmos Activity Builder.

Teachers can adapt and edit digital learning activities developed by Desmos or other users. For example, there exists a sample of digital learning activity in Desmos Activity Builder that has been developed by a user and can be adopted by teachers or other users for teachinglearning of linear programming. Teachers can use the activities by generating a new class code, and then it will be shared with students before the class start. Teachers can use the same activity for different classes by generating different class code. Thus, teachers do not need to create new activities. The teacher can customize the activity to meet the students' needs. Figure 2 shows a view of the Desmos Activity Builder for the linear programming topic.

Desmos provides many video tutorials for teachers to learn more about how to create interactive digital learning activities using Desmos 


\section{desmos}

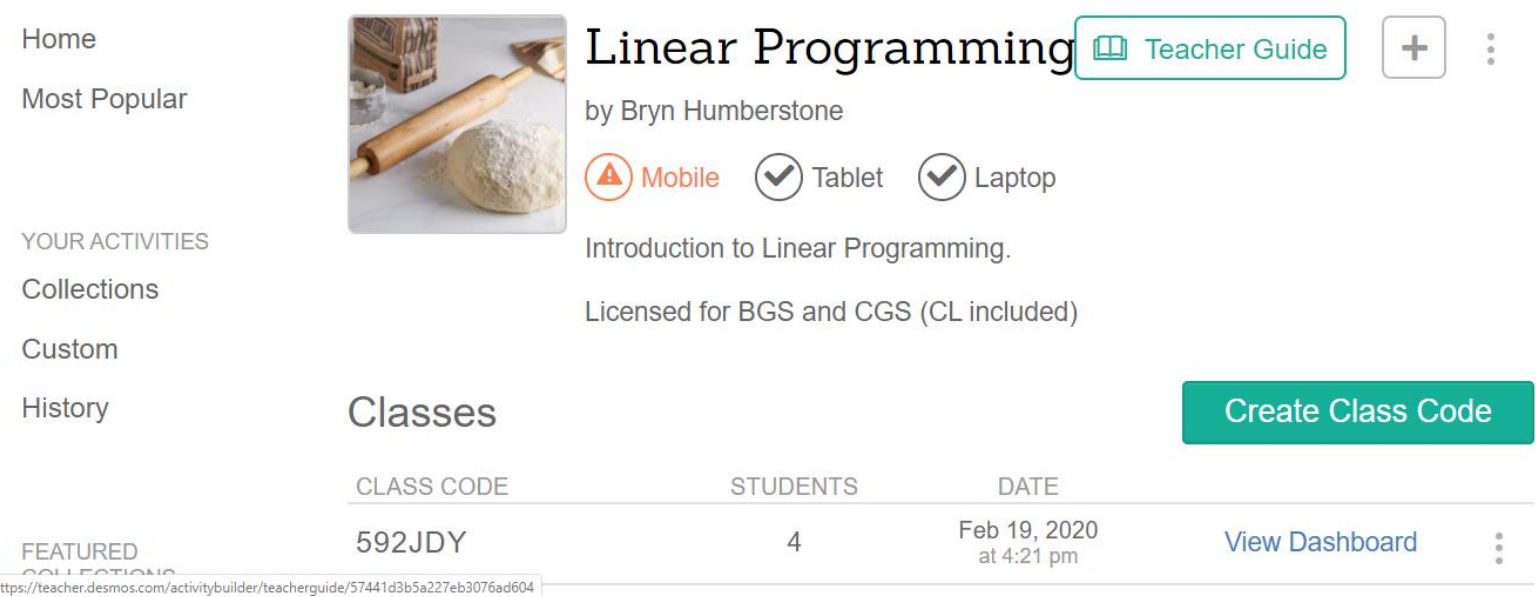

Figure 2. Sample of Desmos Activity Builder for Linear Programming

Table 1. The Triple E Rubric

Engagement in the learning 0=No 1=Somewhat $\quad 2=$ Yes

The technology allows students to focus on the assignment/activity/goals with less distraction (Time on Task).

The technology motivates students to start the learning process.

The technology causes a shift in the behavior of the students, where they move from passive to active social learners (through co-use or co-engagement).

\begin{tabular}{ll}
\hline Enhancement of the learning goals $\quad$ 1=Somewhat $=$ Yes & No
\end{tabular}

The technology tool allows students to develop or demonstrate a more sophisticated understanding of the

learning goals or content (using higher-order thinking skills).

The technology creates supports (scaffolds) to make it easier to understand concepts or ideas (e.g. differentiate, personalize or scaffold learning)

The technology creates paths for students to demonstrate their understanding of the learning goals in a way that they could not do with traditional tools.

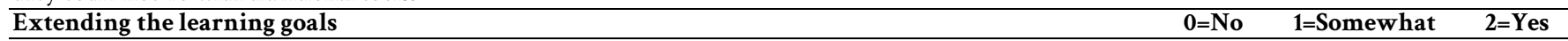

The technology creates opportunities for students to learn outside of their typical school day. (24/7 connection)

The technology creates a bridge between students school learning and their everyday life experiences (connects

learning goals with real life experiences).

The technology allows dtudents to build authentic life soft skills, which they can use in their everyday lives.

READING THE RESULTS

- 13-18 Point: Exceptional connection between learning goals and tool

- 7-12 Points: Some connection between learning goals and tool

- 6 Points or below: Low connection between learning goals and tool

Activity Builder. Teachers can access the potential effectiveness of educational applications in learning, and https://learn.desmos.com/page to find out more about Desmos Activity Builder. Desmos also facilitated many teachers ' professional development programs in the form of free online webinars and training for teachers on how to develop and use Desmos Activity Builder for mathematic teaching-learning.

\section{THE TRIPLE E FRAMEWORK}

Triple E is a framework for teachers to evaluate the degree to which the use of technology supports students to achieve learning goals. Unlike the other technological frameworks, the Triple E Framework's focus is on learning goals and not specific technological tools. This framework stems from an educational study of effective and ineffective practices utilizing technologies over the past two decades. The Triple E measurement rubric was created primarily for teachers and K-12 administrators to be used in developing lesson plans, evaluating the assessing the potential impact of technological tools in lesson plans. This framework consists of three components: Involvement in learning objectives, Improving learning objectives, and Expansion of learning objectives. A recent independent mixed method study conducted in 2018 found Triple E to be valid and reliable.

The following rubric can be used to measure whether technology has a positive impact on student learning goals. The results are to analyze lessons or learning activities that integrate technology in the classroom. The results give teachers information about how well technology supports students to achieve learning goals (see Table 1).

In order to determine if the technology is having a positive impact on student learning goals, the Triple E framework also provides a qualitative analysis which categorizes into three levels as follows: 
Table 2. Desmos Activities Link and Students' Access Code

\begin{tabular}{cccc}
\hline Initial & Desmos Activities Link & Access Code \\
\hline TA & https://teacher.desmos.com/activitybuilder/custom/5e4cc55d050f8617e70244ea & GA68K7 \\
\hline MW & https://teacher.desmos.com/activitybuilder/custom/5e4cde915666613447131d550 & CCNCUY \\
\hline RN & https://teacher.desmos.com/activitybuilder/custom/5e3a723a9d5a4b7639b7e7d7 & BEY4MK \\
\hline AH & https://teacher.desmos.com/activitybuilder/custom/5e3bc72183d5b379632ff9c5 & MH54SY \\
\hline ER & https://teacher.desmos.com/activitybuilder/custom/5e4d2d28766b784a8ccad1aa & FAAJNP \\
\hline
\end{tabular}

\section{Green Level with 13 - 18 Points}

A substantial connection between technology, instructional movements, and learning goals. When a lesson gets at least 13 points, it always fulfils all three components of the Triple E. framework. Therefore, the lesson is perform a remarkable relation between the technology tools, instructional choices around the tool, and students' focus and take-up of the learning goals. Students must be involved as active social learners when tasked with technology integration. Students 'concepts of learning goals must be improved by using technology in such a way that traditional tools cannot perform smoothly, and finally, students' understanding of learning goals must go beyond the classroom so that they connect the things they are learning in a real-life situation.

\section{Yellow Level with 7 - 12 Points}

When a lesson scores between 10 and 12 points, the teacher can conclude that the lesson fulfills at least two of the three components of the Triple E framework. By fulfilling at least two components (most often engagement and enhancement, or engagement and extension), there is a strong connection between technological tools and student learning objectives. When a lesson scores between 7 and 9 points, the lesson usually satisfies the two components of the Triple E framework. Nevertheless, it is quite unusual to meet the two components in all the highest options. Thus, while there is a relationship between technology and learning objectives, educators must take the time to re-evaluate lessons and technology choices and instructional movements to ensure that technology improves and or expands learning objectives in a significant way. There is an opportunity to make additional instructional movements into the lessons to better utilize technology for student learning.

\section{Red Level with 6 Points or Below}

When a lesson gets 6 points or below, it means that the lesson only fulfils one component of the Triple E. framework. In most cases, the lesson only meets the component of involvement, which reflects the weak connection between technology, instructional movement and learning objectives. If this happens, teachers must reconsider integrating certain technologies into the lesson. The teacher can add instructions to improve technology better to improve or expand learning activities. Alternatively, the teacher can use traditional teaching methods (not using technology) if that applies and is possible to meet learning objectives. In particular, because technology tends to praise a lot of time and energy for organizing and implementing, it must be used carefully and deliberately.

\section{RESEARCH METHOD}

The design of this research was using a case study-qualitative research. The researcher generally has a purpose of evaluating the technology product (Desmos Activity Builder) which developed individually by four pre-service teachers. Stake (1995) distinguishes between collective, intrinsic and instrumental case studies. The study set out to answer the following research question: how well the Desmos Activity Builder developed by mathematics pre-service teachers meet the learning goals in Linear Programming lesson according to the Triple E Framework?

Thus, to answer the research question, the research was conducted in one of Indonesia private teacher education institution (LPTK) which affiliated with an international university in the United States. The population of this study is pre-service mathematics teachers in that LPTK. The researcher applied the convenience sampling procedure and got five selected research respondents. The respondents were preservice mathematics teachers who enroll in Linear Programming course. In the first session, the pre-service teachers were introduced to the Linear Programming problems involving two variables and learned about how to get the optimum solution graphically. In the second session, the researcher has performed a simulation of the Linear Programming lesson, which integrated the Desmos Activity Builder and set the pre-service teachers as secondary students. The pre-service teachers were assigned individually to create a Desmos Activity Builder which can be used to teach Linear Programming in secondary mathematics school. The details requirements of the assignments, including the rubric of Triple E framework, were informed to the preservice teachers through the Learning Management System (LMS). As a final activity, the pre-service teachers were asked to do self-assessment of his/ her own product, specifically by measuring how well the Desmos Activity Builder help students to meet the learning goals.

In qualitative research, the researcher became part of research instruments. Researchers as research instruments were to establish the focus of research, select respondents, conduct data collection, assess data quality, analyze data, interpret data, and draw conclusions based on the research findings (Sugiono, 2009, p. 306). Data were collected qualitatively from participants' work (Desmos Activity Builder for Linear Programming lesson) and its assessment according to the Triple E framework. These data were triangulated by looking at the assessment results from three experts (researcher and other lecturers) using the Triple E framework. Both descriptive statistics and content analysis were carried out to analyze the pre-service teachers' products (Desmos Activity Builder), both descriptive statistics and content analysis of the products were carried out.

\section{RESULTS}

Table 2 show the data of pre-service teachers' Desmos Activities along with students' access code.

Figures 3-7 shows the $1^{\text {st }}$ screen of each Desmos Activity Builder developed by the pre-service teachers. 


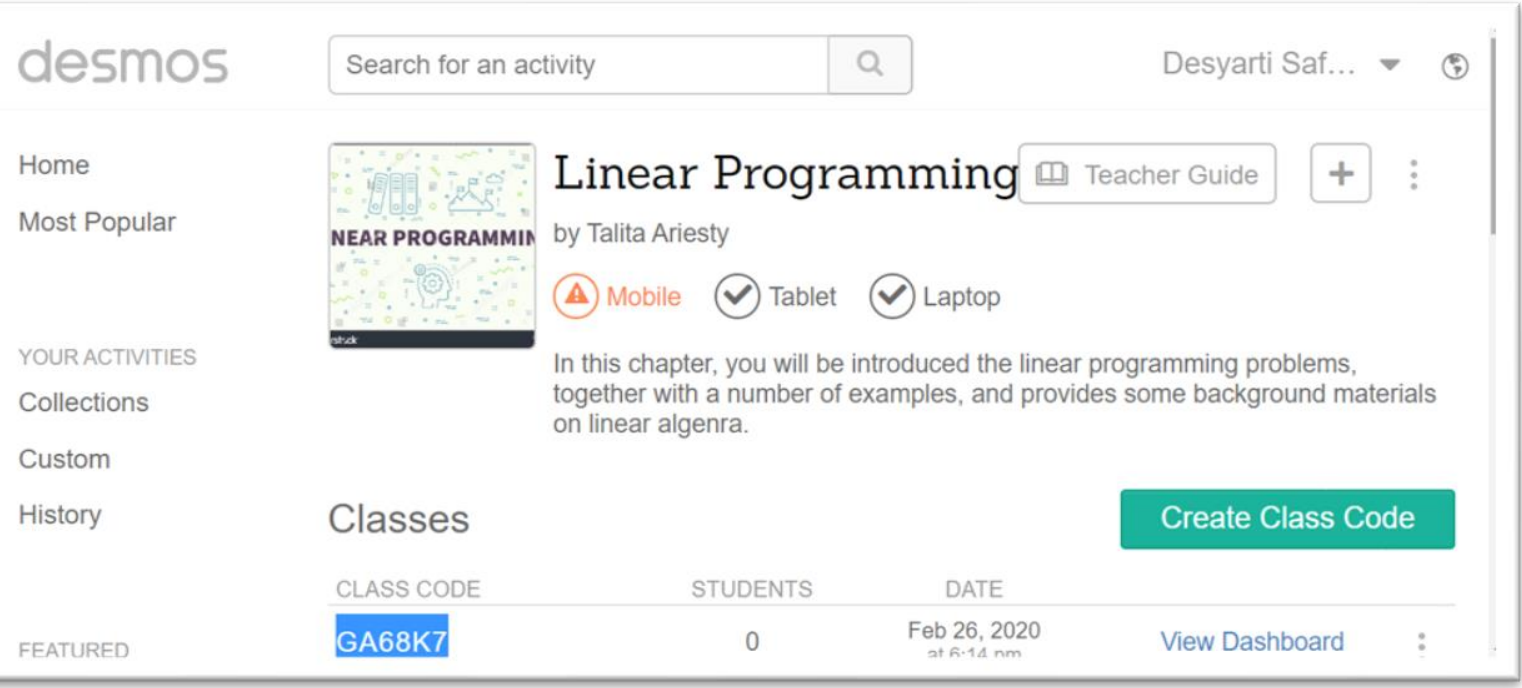

Figure 3. Desmos Activities developed by TA

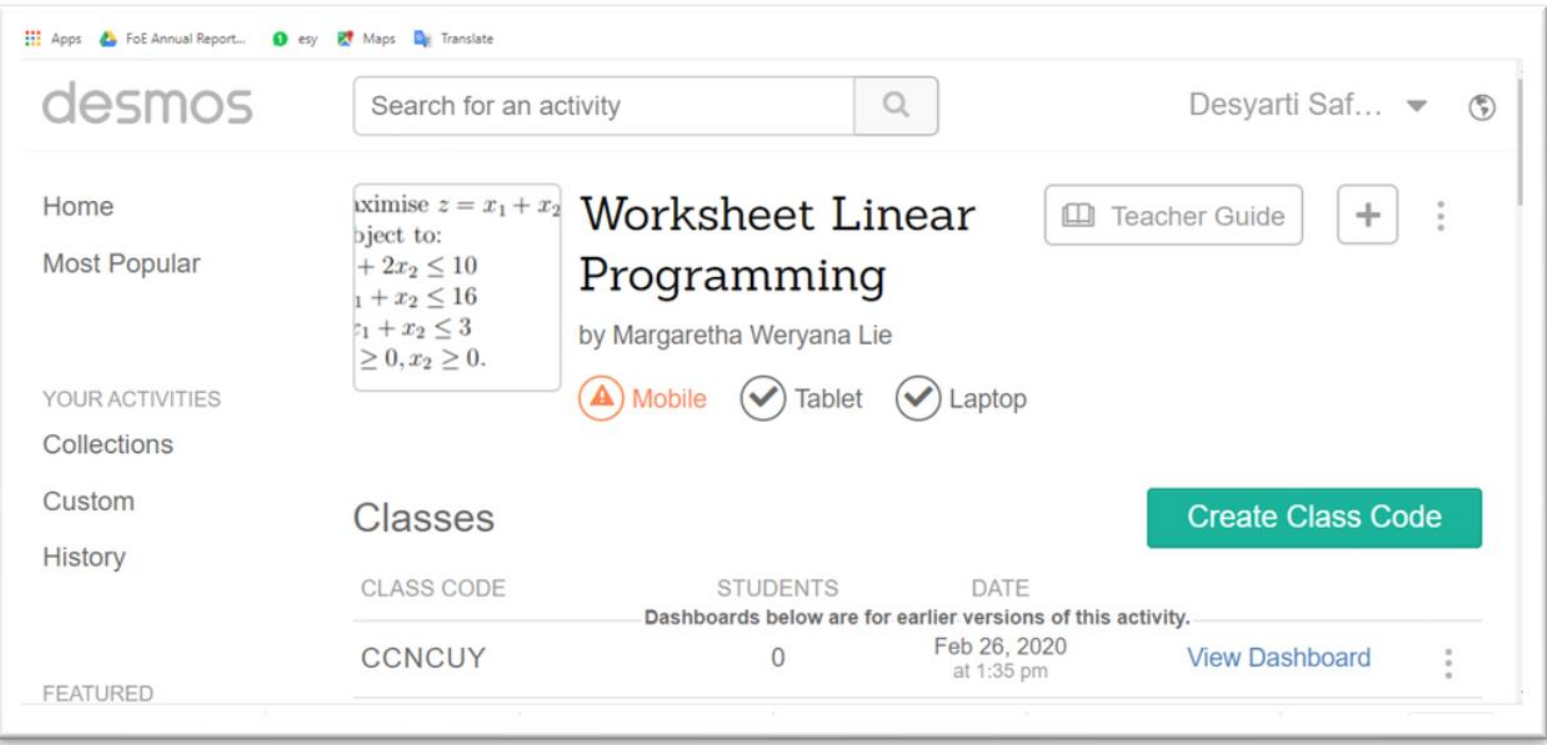

Figure 4. Desmos Activities developed by MW

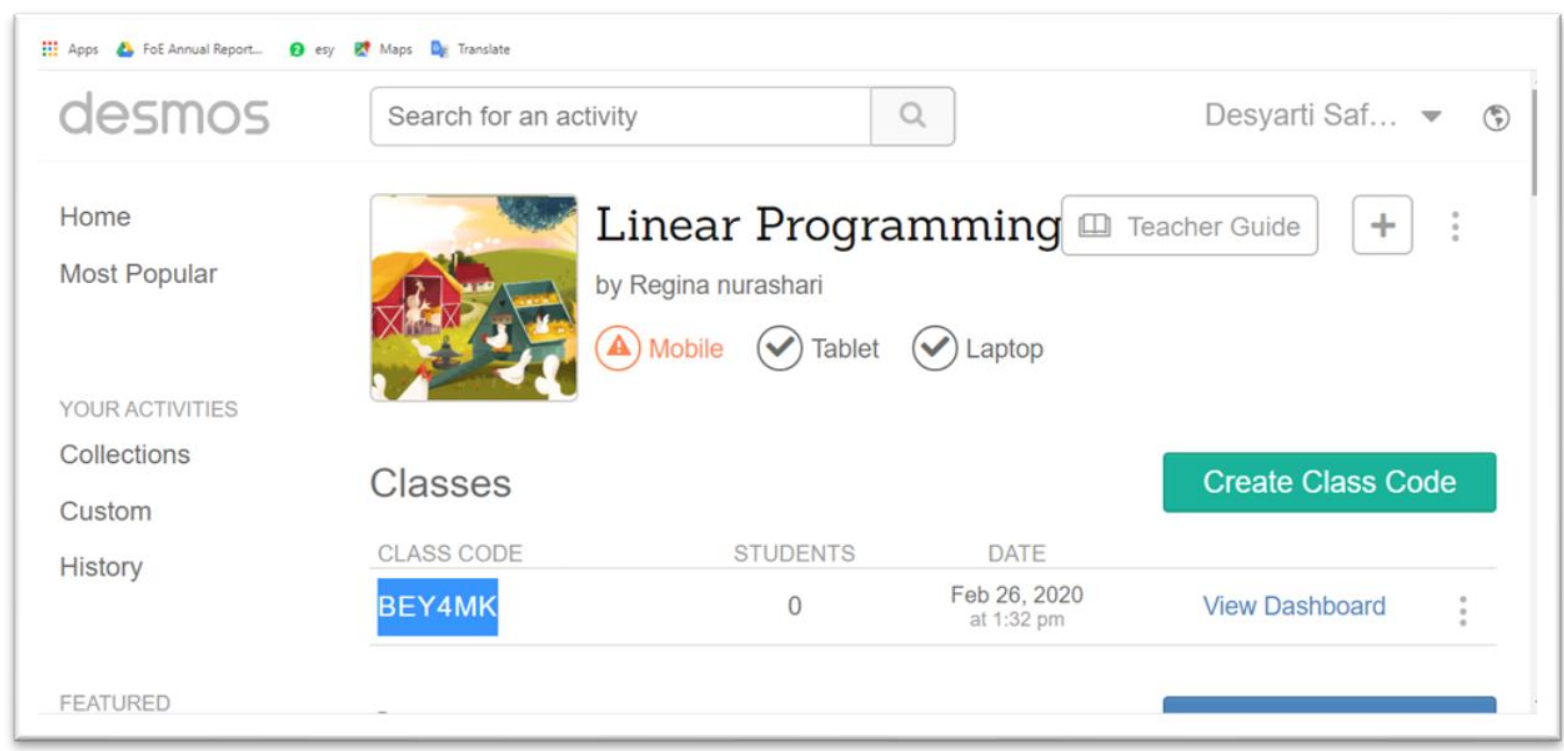

Figure 5. Desmos Activities developed by RN 


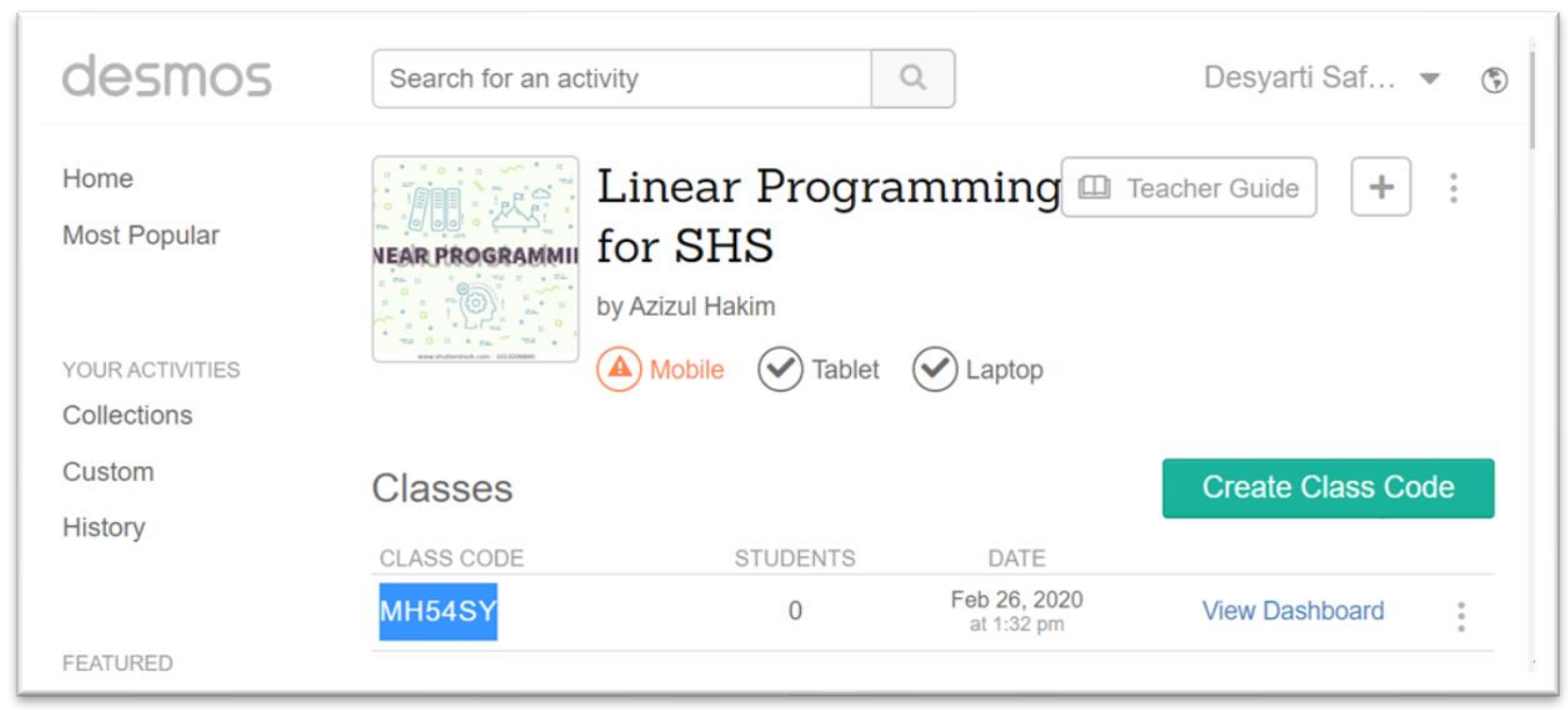

Figure 6. Sample of Desmos Activity Builder for Linear Programming

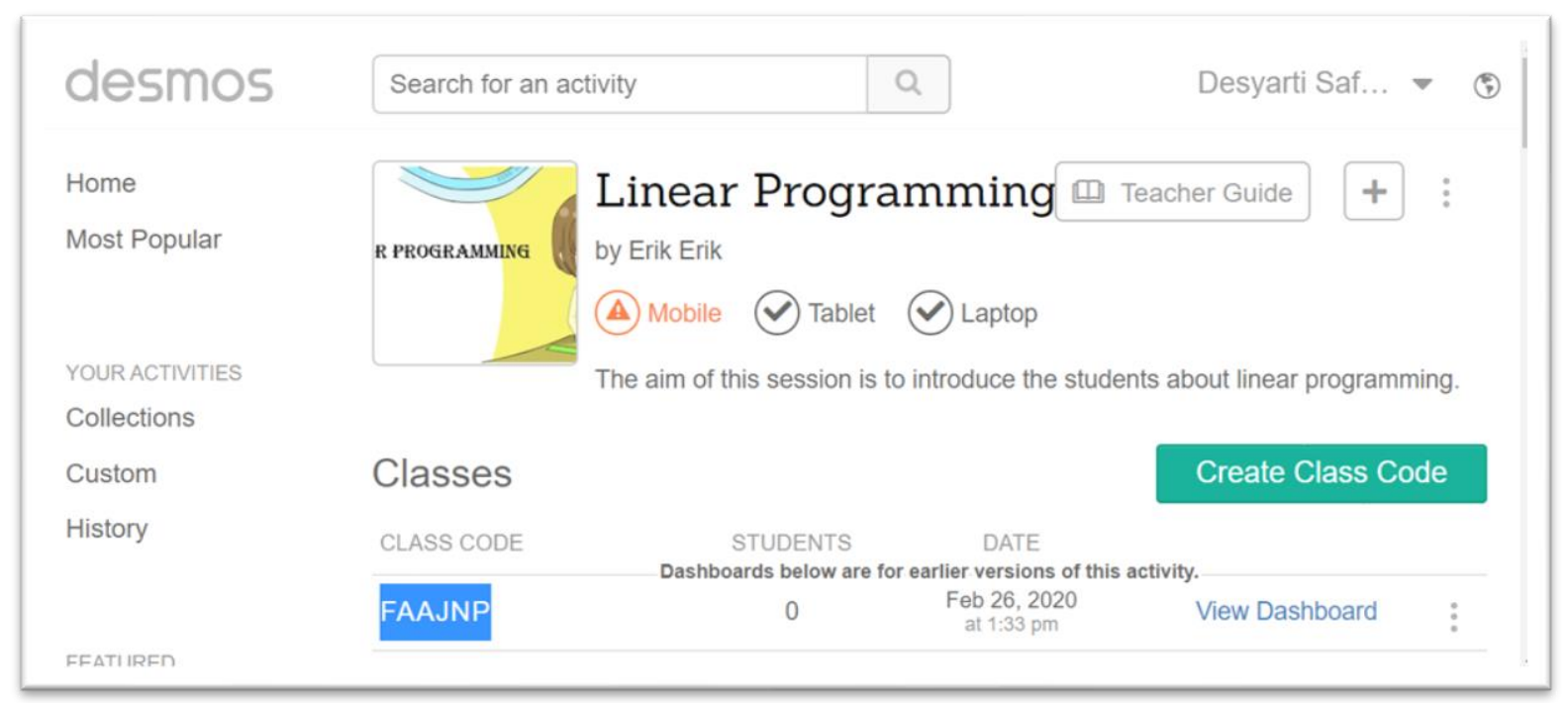

Figure 7. Desmos Activities developed by ER

Based on the experts' analysis, all pre-service teachers have achieved scores greater than 12 points with scores range between 14 and 16. These achievements were categorized in green level, which implies that there exists an exceptional connection between learning goals and the Desmos Activity Builder they have developed. As defined in the Triple E framework, these lessons perform a remarkable relation between the technology tools, instructional choices around the tool, and students' focus and take-up of the learning goals. Students should be engaged as active time-on-task social learners by technology integration. Students concept of the learning goals should be elevated by the use of technology in such ways that traditional tools could not smoothly perform, and finally, students understanding of the learning goals should go beyond the classroom so that they are connecting things they are learning to their everyday life.

A more details analysis of the pre-service teachers' Desmos Activity Builder products are described as follows:

- For engagement aspect, all pre-service teachers were able to develop Desmos Activities which allows students to focus on the assignment or activity with less distraction and causes a shift in the behaviour of the students, where they move from passive to active social learners. Almost all features of the Desmos Activity Builder were appropriately utilized by all pre-service teachers, thus they produced lessons that keep students actively engage in the learning process. However, three out of five pre-service teachers' activities were somewhat able to motivates students to start the learning process. MW provides a video at the beginning of the activities, but unfortunately, the video did not show the real-life application of linear programming. The video only focused on reviewing the inequalities concept, which might be less motivates students to learn about the Linear Programming topic. In the case of TA and $\mathrm{AH}$, it was found that they provide some real-life problems dealing with linear programming concept, but they did not provide an interesting video or picture or activities in the 1st screen of their activities which may give higher motivation to students to learn about linear programming.

- For extension aspect, all pre-service teachers were able to develop Desmos Activities which creates a bridge between students school learning and their everyday life experiences. They did it by giving some real-life applications of linear programming problem 
Table 3. Assessment Results according to The Triple E Framework

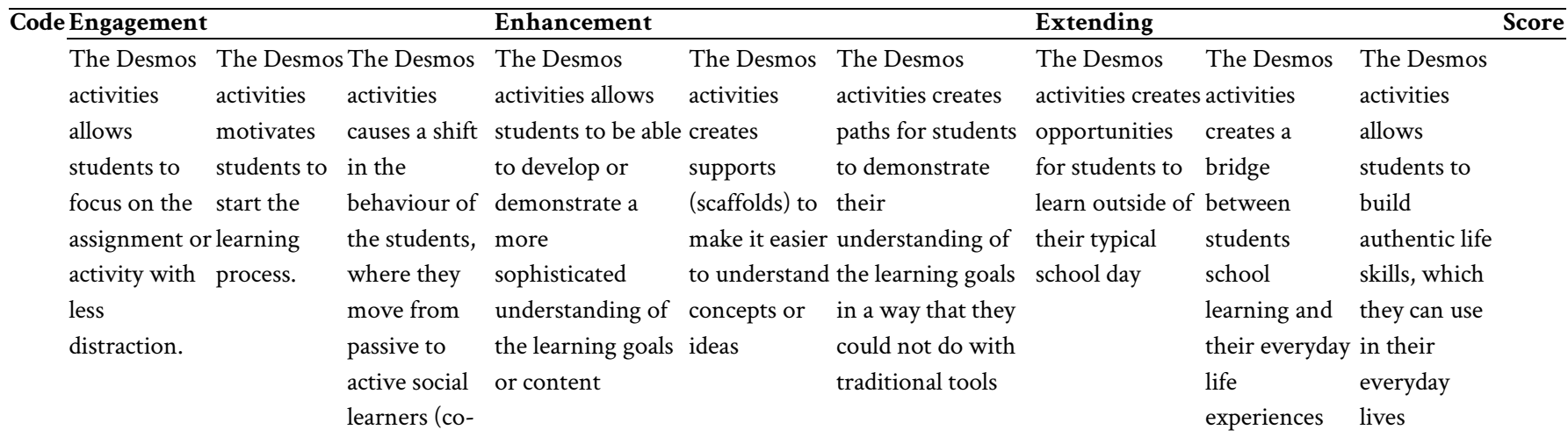

\begin{tabular}{|c|c|c|c|c|c|c|c|c|c|}
\hline TA & Yes & Somewhat & Yes & Yes & Somewhat & Yes & Somewhat & Yes & Somewhat \\
\hline MW & Yes & Somewhat & Yes & Yes & Yes & Yes & Somewhat & Yes & Somewhat \\
\hline $\mathrm{RN}$ & Yes & Yes & Yes & Yes & Yes & Yes & Somewhat & Yes & Somewhat \\
\hline $\mathrm{AH}$ & Yes & Yes & Yes & Yes & Yes & Yes & Somewhat & Yes & Somewhat \\
\hline ER & Yes & Somewhat & Yes & Yes & Yes & Yes & Somewhat & Yes & Somewhat \\
\hline
\end{tabular}

which should be solved by students. Nevertheless, most of them were unable to perform well in other two sub-aspects: to build authentic life skills, which they can use in their everyday lives and opportunities for students to learn outside of their typical school day. Most of the activities were clearly seen provides opportunities for students to develop problem-solving and collaboration skills.

- For enhancement aspect, all pre-service teachers were able to develop Desmos Activities which allows students to be able to demonstrate a more sophisticated understanding of the learning goals or contents and creates paths for students to demonstrate their understanding of the learning goals in a way that they could not do with traditional tools. They start the lessons by giving a reallife application of linear programming (through problems or videos), they utilized the graph and sketch features which promotes students' understanding about inequalities and how to get the feasible region, they utilized table, input, and choice features to gather students' ideas with various strategies. Some of them also use card sort feature which encourages students to demonstrate their understanding in an interesting way. Only one pre-service teacher (TA) whose activities somewhat creates supports (scaffolds) to make it easier to understand concepts or ideas. TA start the activities by giving an application problem of linear programming topic, and the second screen directly provides the solutions to the students. Thus, it will be better if TA gives step-by-step activities that scaffolds student to answer the given problem.

Although all pre-service teachers were able to develop Desmos Activities with positive impacts on students' learning goals, there exists room for future improvement, especially in extending aspect. They might modify the activities such a way to give more opportunities for students to learn outside of their typical school day and allows students to build authentic life skills, which they can use in their everyday lives. Besides that, the pre-service teachers also need to think more creatively to select or to design opening activities that motivate students to learn about linear programming and give more smooth transition which better scaffold students to understand the concept.

As mentioned earlier, besides being assessed by the experts, preservice teachers were also asked to do self-assessment on their Desmos Activities. One of the pre-service teachers (RN) seems not entirely confident with her activities and give her own score 11 points and categorized it in yellow level. In contrast, according to the experts evaluation, $\mathrm{RN}$ was eligible to get 16 points and categorized in green level. The other four pre-service teachers give a score of more than 12 points for their activities and categorized in green level. Table 4 shows the results of pre-service teachers' self-assessment on their Desmos Activities.

It was known that some pre-service teachers did not sure whether their activities can motivate students to start the learning process. Thus, they put "somewhat" for this sub-engagement component. Most of them also sure that their lesson will make students focus on the given assignments or activities and actively engage in the learning process. Below are their brief statements regarding to engagement aspect:

TA: The activities such as real-world problem in the first slide, worksheet and graphic assignment engage student to learn linear programming to be more excited.

MW: The students will be engaged because the video material is simple and easy to follow with short duration, so that they don't have to be stress from the beginning of the activity.

$\mathrm{RN}$ : They have to answer question, match the cards, and play interactive games.

$\mathrm{AH}:$ In this Desmos activities, I think that these activities will have less distraction, but I do not know the students' learning style and characteristic so that is why I chose somewhat.

ER: These activities also can be motivated for students because they can learn mathematical topics using technology, it depends on their background if they already know and experiences on learning mathematics using technology, I think it would be less motivated or even more motivated.

All pre-service teachers were agreed that the Desmos Activities they have developed could supports (scaffolds) students to understand concepts or ideas and also creates paths for students to demonstrate their understanding of the learning goals in a way that they could not do with traditional tools. Some of them said that they use some features (graph, sketch) in Desmos Activity Builder to enhance students learning. They even provide additional video, application problems, and image to visualize the application of linear programming. AH and ER also confirmed that they present step-by-step activities to scaffold students in order to help students understand the concept. Below are some brief self-assessments on enhancement aspect: 
Table 4. Pre-Service Teachers' Self-Assessment According to The Triple E Framework

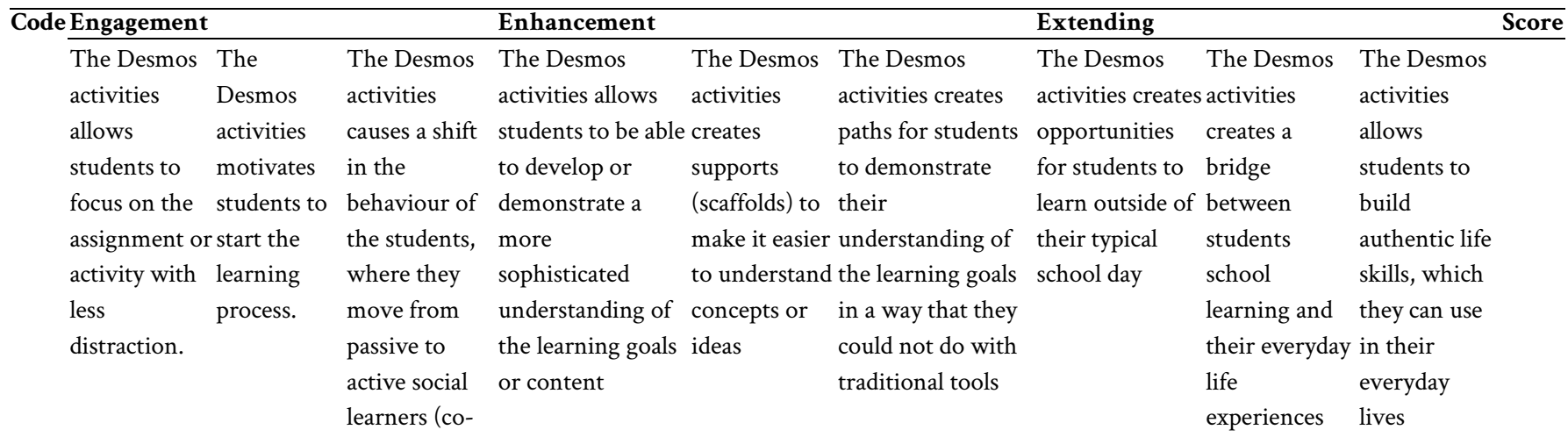

\begin{tabular}{|c|c|c|c|c|c|c|c|c|c|c|}
\hline TA & Yes & Yes & Somewhat & Yes & Yes & Yes & Yes & Yes & Yes & 17 \\
\hline MW & Yes & Somewhat & Yes & Somewhat & Yes & Yes & Somewhat & Somewhat & Yes & 14 \\
\hline $\mathrm{RN}$ & Yes & Somewhat & Somewhat & Somewhat & Yes & Yes & Yes & Somewhat & No & 11 \\
\hline $\mathrm{AH}$ & Somewhat & Somewhat & Yes & Yes & Yes & Yes & Somewhat & Somewhat & Somewhat & 13 \\
\hline$\overline{E R}$ & Yes & Yes & Yes & Somewhat & Yes & Yes & Yes & Somewhat & Somewhat & 15 \\
\hline
\end{tabular}

TA: The use of technology enhances the process of learning for students. Nowadays, students are more excited to learn with technology rather than in a traditional way.

MW: The feature in the Desmos Activity Builder provide interactive that is useful for the enhancement since it is accessible compared to traditional tools.

RN: They can use the graph feature immediately on the platform and submit it easily.

AH: In this Desmos Activities, the students are provided a brief explanation about LP through video, and after that the students are asked to follow the rest of the activities. In these activities, students are guided to learn solving LP step-by-step, such as watching video to know what is LP and how to make constraint from a story problem, creating a graph of LP problem to see the intersect and feasible region, estimating the optimum solution of the given LP, and after that the next activities, the students learn to solve LP by interpreting the table into mathematical models, scathing without helping from Desmos which they need to draw by themselves, and ordering the possible solution of the LP. These activities are expected to help students learn step-by-step and make them understand how to solve LP in many ways.

ER. From one linear programming problem, I divided the problem into some part, such as labelling $x$ and $y$, making constraint, making objective function, sketching the graph, and finding the optimum solution.

Most of the pre-service teachers were not sure that the Desmos Activities they have developed creates a bridge between students school learning and their everyday life experiences. They also did not really sure that the activities give opportunities for students to learn outside of their typical school day and allows students to build authentic life skills. They were just capturing that they provide some real-life application which represents the linear programming problem. Only TA said that students can learn how to manage time efficiently while learning Linear Programming through the Desmos Activities. Below are some brief self-assessments on extending aspect:

TA: Not only learn linear programming, but students also learn how to sketch graph using technology. Besides that, students also learn how to manage time when learning LP using Desmos Activities.

MW: Since it is still the introduction of the LP, the material provided in the activity is still the basic one so it is still far to say that the activity could lead them to build the authentic life skills.

RN: The Desmos Activity Builder is using real problems, and they will be able to check their understanding independently through the assignments provided.
$\mathrm{AH}$ : In these activities, there only a few questions that related to the daily life, and it also not really related with students daily life. However, these activities can be a new insight for them to know that some problem in daily life can be solved by using LP.

ER: I think that student will have ability to solve the problem related to linear programming because linear programming is contextual problem that related to our life which is real world problem. From my activity, I used the linear programming problem about product $\operatorname{mix}$

\section{DISCUSSION}

Based on expert analysis, all pre-service teachers have reached the green level, which implies that there is an extraordinary relationship between the Desmos Activity they have developed and the expected learning objectives. For the engagement aspect, all pre-service teachers can develop Desmos Activities that allow students to focus on assignments or activities with fewer distractions and cause changes in student behaviour, where they move from passive social students to active ones. Danielson and Meyer (2016) claimed that during Desmos Activities, students could share ideas, ask questions of one another, and challenge one another in productive and exciting ways. Almost all Desmos Activity Builder features are used appropriately by the preservice teachers to get students actively involved in the learning process. Nevertheless, some activities are considered somewhat able to motivate students to start the learning process. They can fix this by giving videos, pictures or real application problems from the topic of Linear Programming as did the other two pre-service teachers. Most of them were sure that their activities would make students focus and actively engage in the learning process.

Regarding the enhancement aspect, all pre-service teachers can develop Desmos Activities that enable students to be able to demonstrate a more sophisticated understanding of Linear Programming content in ways that they cannot do with traditional tools. As mentioned by Ebert (2014), Desmos is an easy-to-use, intuitive, powerful tool that should be explored by any mathematics teacher who teaches the graphing of equations. All pre-service teachers have used graphics and sketch features which are potent to explore the inequalities and enhance students' understanding of how to gain the 
feasible region. They used table, input, and choice features to gather students' ideas with various strategies. Some of them also used a cardsort feature to promote students to show their understanding in attractive ways. All pre-service teachers claimed that their activities provided ample scaffolding for students to understand the concept of Linear Programming better. Desmos Activity Builder has proven especially useful by allowing teachers to provide students with opportunities to struggle productively, create, error-check, and think deeply to learn mathematics (Orr, 2017).

In terms of extension aspect, all pre-service teachers can develop Desmos Activities which creates a bridge between student learning at school and their daily life experiences. They realized it by giving several real-life applications of Linear Programming problems. Nevertheless, most of them cannot work well in two other sub-aspects: to build authentic life skills and opportunities for students to study outside their usual school days. All pre-service teachers did not realize that the activities they have developed can provide opportunities for students to develop problem-solving and collaboration skills. Nonetheless, one pre-service teacher claims that students can learn how to manage time efficiently while learning Linear Programming through Desmos Activities.

Some studies have shown that pre-service teachers have demonstrated confidence and intention to integrate technology for student-centred learning. Choy et al. (2009) found that pre-service teachers have a positive intention to incorporate technology into their future teaching to facilitate student-centred learning. As indicated, preservice teachers possess technical knowledge and positive attitudes toward technology use in mathematics classes. However, the lack of knowledge and experiences about how to teach mathematics effectively (Choy et al., 2009) can also be an obstacle to technology integration. Effective integration of technology in teaching and learning process requires teachers' interrelated and specialized knowledge. Pre-service teachers need to improve their knowledge of mathematics, how students think about and learn mathematics with/without technology, and how to use technology to teach mathematics. Just owning knowledge, however, would not be enough. Pre-service teachers also need to view mathematics as a continually expanding field in which students can construct their mathematics through active engagement, teachers can facilitate students' conceptual learning, and technology can support student-centred approaches. Thus, pre=service teachers should develop all areas of content, pedagogy, and technology in their beliefs and knowledge to be able to use technology effectively to teach mathematics.

There is room for future improvement, especially in extension aspect. Researchers believe that knowledge should be produced through authentic context and tasks (Brown, Collins, \& Duguid, 1989; Lave \& Wenger, 1990). Technological tools need to encourage meaningful learning, where technology expands learning from pre-existing knowledge and helps them create new knowledge (Wartella, 2015). Pre-service teachers might modify activities in such a way as to provide more opportunities for students to study outside of regular school activity and allow students to build authentic life skills. Pre-service teachers also need to think more creatively to choose or design initial activities that gain students' attention and provide a smoother transition that better scaffold students to understand concepts.

Although there are constraints to doing so, there is substantial value in aligning the Linear Programming course assignment related to the use of Desmos Activity Builder. Pre-service teachers experience the benefits of learning through creating digital learning activities for linear programming topic by using Desmos Activity Builder. There is a potential to optimize pre-service mathematics teacher readiness to develop and use technology by providing opportunities for them to think about, design, experience, and reflect on how they can use technology for learning and teaching. Taylor's (2004) claim that a series of experiences contribute to the development of pre-service teachers, "especially university-based teaching, carrying out tasks related to literature research and teaching experience using technology with their classrooms" (p. 54).

\section{CONCLUSION}

All pre-service teachers have reached the green level of the Triple E Framework, which implies that there are extraordinary connection between the Desmos Activities they have developed and the expected learning goals. Even though they have demonstrated confidence to integrate technology in their lesson, future improvement is needed, especially in the extension aspect. Pre-service teachers might modify activities in such a way: to provide more opportunities for students to study outside of regular school activity, allow students to build authentic life skills, and provide a smoother transition that better scaffold students to understand Linear Programming concepts.

A critical closing point is that the development of pre-service teacher capacity to use technology in teaching-learning of mathematics occurs as a result of the Linear Programming course assignment. Instead, this development occurs through a combination of experiences, together with reflections on these experiences. This study shows that there is potential to optimize pre-service mathematics teacher readiness to develop and use technology by providing opportunities for them to think about, design, experience, and reflect on how they can use technology for learning and teaching.

\section{REFERENCES}

Association of Mathematics Teacher Educators' Technology Committee. (2005). Draft position statement titled Preparing Teacher to Use Technology to Enhance the Learning of Mathematics.

Brown, J. S., Collins, A. and Duguid, P. (1989). Situated cognition and the culture of learning. Educational Researcher, 18(1), 32-42. https://doi.org/10.3102\%2F0013189X018001032

Carpenter, T. P., Corbitt, M. K., Kepner, H. S., Lindquist, M. M., \& Reys, R. E. (1981). National assessment. In E. Fennema (Ed.), Mathematics education research: Implications for the 80's (pp. 22-38). Reston, VA: National Council of Teachers of Mathematics.

Choy, D., Wong, A. F. L., \& Gao, P. (2009). Student Teachers' Intentions and Actions on Integrating Technology into Their Classrooms during Student Teachings. Journal of Research on Technology in Education, 42(2), 175-195. https://doi.org/10.1080/15391523.2009.10782546

Danielson, C., \& Meyer, D. (2016). Increased Participation and Conversation Using Networked Devices. Mathematics Teacher, 110(4). https://doi.org/10.5951/mathteacher.110.4.0258

Ebert, D. (2014). Graphing Projects with Desmos. Mathematics Teacher, 108(5). https://doi.org/10.5951/mathteacher.108.5.0388 
Gulati, S. (2017). Desmos Activity Builder Create Your Own Interactive Activity. At Right Angle, 6(3). Retrieved from https://azimpremjiuniversity.edu.in/SitePages/resources-aranovember-2017-desmos-activity-builder.aspx

International Society for Technology in Education. (2008). National educational technology standards for teachers. Retrieved from http://www.iste.org/standards/nets-for-teachers.aspx

Jon Orr. (2017). Function Transformations and the Desmos Activity Builder. The Mathematics Teacher, 110(7), 549. https://doi.org/10.5951/mathteacher.110.7.0549

King-Sears, M. (2009). Universal design for learning: Technology and pedagogy. Learning Disability Quarterly, 32(4), 199-201. https://doi.org/10.2307/27740372

Lave, J. and Wenger, E. (1991). Situated learning: Legitimate peripheral participation. Cambridge: Cambridge University Press. https://doi.org/10.1017/CBO9780511815355

National Council of Teachers of Mathematics (NCTM). (2000). NCTM Principles and standards for school mathematics. Reston, VA: Author.
Wartella, E. (2015). Educational Apps. Psychological Science in the Public Interest, 16(1), 1-2. https://doi.org/10.1177/1529100615578662

Roschelle, J., Shechtman, N., Tatar, D., Hegedus, S., Hopkins, B., Empson, S., Knudsen, J., \& Gallagher, L. (2010). Integration of technology, curriculum, and professional development for advancing middle school mathematics: Three large-scale studies. American Educational Research Journal, 47(4), 833-878. https://doi.org/10.3102/0002831210367426

Suh, J. M. (2010). Tech-Knowledgy and Diverse Learners. Mathematics Teaching in the Middle School, 15(8), 440-447. https://doi.org/10.2307/41183517

Taylor, L. (2004). How student teachers develop their understanding of teaching using ICT. Journal of Education for Teaching, 30(1), 43-56. http://dx.doi.org/10.1080/0260747032000162307

Learn Desmos: Activities. (n.d.). Retrieved from Desmos: https://learn.desmos.com/teacher-v1

Triple E Framework. (n.d.). Retrieved from Triple E Framework: https://www.tripleeframework.com/ 